\title{
Early warning of impending flash flood based on AloT
}

\author{
Wen-Tsai Sung ${ }^{1}$, Ihzany Vilia Devi ${ }^{1}$ and Sung-Jung Hsiao ${ }^{2 *}$ (D)
}

\section{*Correspondence:}

sungjung@gs.takming.edu.

tw

${ }^{2}$ Department of Information

Technology, Takming

University of Science

and Technology, Taipei

City 11451, Taiwan

Full list of author information

is available at the end of the article

\begin{abstract}
According to data from the Earth's Volcano and Geological Disaster Reduction Center, a country like Indonesia has experienced many natural disasters, one of which is flooding. Floods are an annual natural disaster, especially on mountain slopes. Mountainous areas experience more dangerous than floods than the urban areas because they can cause other natural disasters, such as landslides and damage the hiking trails. The steep and winding roads minimize and limit the number of officers working in the mountains. Therefore, flood detection and monitoring equipment is needed. The proposed system based on AloT technology provides real-time flood analysis so that the authorities can monitor residents around mountainous areas and provide early warning. This research focuses on the flood observation system as an early warning system to effectively monitor the flood-prone mountain slopes in real time while taking into account the cost, time efficiency, and safety measurement. The proposed system design includes the integration of sensors into the microcontroller, and the communication between the posts using LoRa and SIM900 sends data to the cloud server via the Internet. All sensor readings for each post are displayed on the app, and alerts are sent via SMS and the app.
\end{abstract}

Keywords: AloT, LoRa, Tilt sensor, Rain gauge sensor, Water flow sensor

\section{Introduction}

Due to the global greenhouse effect, the earth's climate is abnormal, so this phenomenon has caused continuous natural disasters around the world. In fact, many residents live in mountainous areas worldwide. Among the many natural disasters occurring on the earth, flood is one of them. Flooding is a natural disaster that often occurs on the earth; for instance, in Indonesia, it occurs not only in cities but also in mountainous areas. One of the factors affecting flooding is rainfall. The greater the rainfall, greater is the flood flow which the more serious the direct or indirect damage to the land [1]. According to Pannagos et al., the energy input of the earth's surface exposed to rainfall is one of the key factors in controlling water erosion [2]. People living on hillsides in mountainous areas include dense population, high poverty rates, highly dependent on climate-sensitive resources, lack of awareness of climate risks, unplanned urbanization and poor infrastructure, and experience many other disadvantages. Most farmers, fishermen, small business owners, and other communities living in low-lying

(c) The Author(s) 2022. Open Access This article is licensed under a Creative Commons Attribution 4.0 International License, which permits use, sharing, adaptation, distribution and reproduction in any medium or format, as long as you give appropriate credit to the original author(s) and the source, provide a link to the Creative Commons licence, and indicate if changes were made. The images or other third party material in this article are included in the article's Creative Commons licence, unless indicated otherwise in a credit line to the material. If material is not included in the article's Creative Commons licence and your intended use is not permitted by statutory regulation or exceeds the permitted use, you will need to obtain permission directly from the copyright holder. To view a copy of this licence, visit http:// creativecommons.org/licenses/by/4.0/. 
waterlogged areas feel the brunt of widespread climate change because of global warming and flooding in these areas, especially flash floods. Flash floods are caused by the main and triggering factors that determine their location, frequency, and scale. High-intensity rainfall is the main source of flash floods in hilly areas, especially landslides in areas with loose rocks [3].

Reducing the risk of flood disasters is carried out by constructing and structuring building facilities and infrastructure and requires spatial planning based on disaster mitigation as an effort to improve life safety and comfort and preserve the environment. Therefore, in this study, we aimed to analyze and monitor flooding on the slopes of the mountains by measuring the height and velocity of the water and periodically monitoring the rain using Artificial Intelligence Internet of Things (AIoT) technology. Disasters will not stop just because of the use of IoT technology, but this technology can help predict early warning systems and disasters such as floods [4]. The functioning of this tool is shown in Fig. 1. It works by coordinating multiple nodes using long range (LoRa) communication technology. LoRa is one of the low-power wide-area network (LPWAN) communication systems with long-distance transmission capabilities. Although LoRa technology still has shortcomings in secure localization systems, ZigBee comparisons reveal that the reliability for LoRa technology can be increased up to $45 \%$ so that it can meet the required system unit specifications [5, 6]. The communication between posts using LoRa and SIM900 sends data to a cloud server via the internet. Furthermore, all sensor readings of each post are displayed on the App, and alerts are sent via short message service (SMS) and via the App. Moreover, each node has sensors to measure rainfall, water flow rate, and water velocity in determining the potential for flooding in an area connected to LoRa, as shown in Fig. 1.

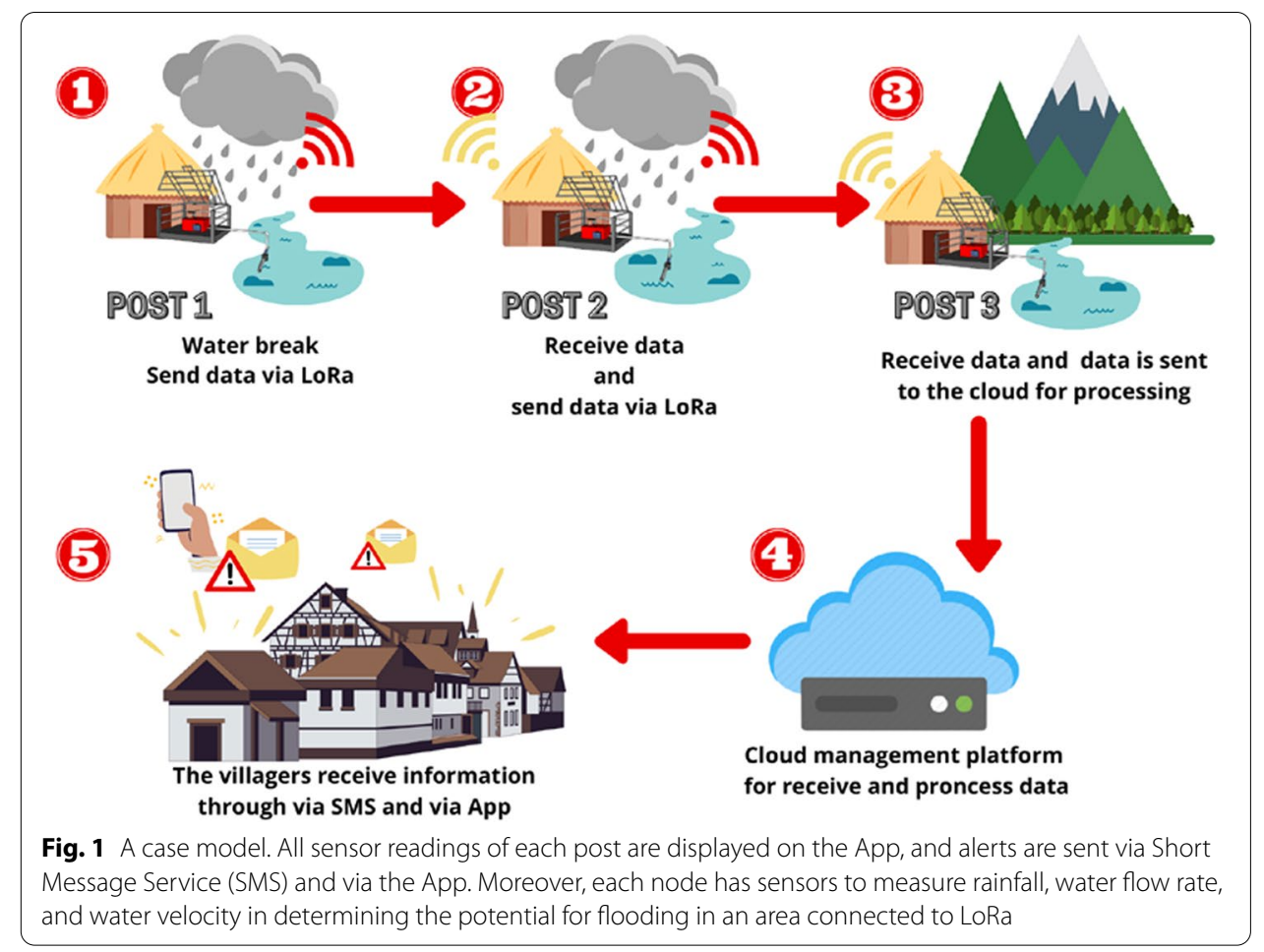


The method of this paper is to use a fuzzy approach to implement various modes of intelligent control. The proposed system uses a fuzzy algorithm to calculate which output control signal the input signal of each environmental sensing device should correspond to. The system will execute various early warning hardware or communication devices according to the output control signal. Therefore, the system will achieve the protection goal of active sensing and intelligent early warning.

\section{Method of using fuzzy}

The proposed early warning system for flash floods is an architecture that uses a network of sensors to integrate with the Internet. In this section, we describe the use of fuzzy methods to calculate and analyze various environmental variables. In this method, the input and output variables of fuzzy control must be specified, and the variable elements are set according to the optimal range of growth. The fuzzy set is shown in Table1. There are four inputs and one output was used in this system. The first input is rainfall intensity, water speed, water level, and steeper slopes or relief. The output on this system is a warning system which is classified into three categories, namely normal, cautious, and dangerous. Table 2 shows the range of input membership functions, wherein, we can see the size range of each existing prefix. The rules were generated from logical reasoning and expert knowledge; some of these fuzzy rules are listed in Table 3. The advantages of using fuzzy control are: on the one hand, it does not require an accurate mathematical model, and on the other hand, it can integrate the knowledge of human experts into the design process of the controller. When performing fuzzy control, the behavior of the controlled system is described by a set of fuzzy rules, and these fuzzy rules use semantic fuzzy information instead of mathematical equations. Therefore, the knowledge of human experts can be converted into fuzzy control rules, which reduces the complexity of designing the control system. However, in many applications of fuzzy systems, the

Table 1 Input and output fuzzy sets

\begin{tabular}{|c|c|c|c|}
\hline Prefix & & & Description \\
\hline Input & Rainfall intensity $(\mathrm{mm} / \mathrm{d})$ & $\begin{array}{l}\text { Small } \\
\text { Moderate } \\
\text { Heavy } \\
\text { Storm } \\
\text { Large storm }\end{array}$ & $\begin{array}{l}\text { Refers to the intensity of rainfall measured by the rain gauge } \\
\text { sensor }\end{array}$ \\
\hline & Water speed $(\mathrm{m} / \mathrm{s})$ & $\begin{array}{l}\text { Slow } \\
\text { Average } \\
\text { Fast }\end{array}$ & $\begin{array}{l}\text { Refers to the speed of the floodwaters measured by the } \\
\text { water flow sensor }\end{array}$ \\
\hline & Water level (cm) & $\begin{array}{l}\text { Low } \\
\text { Average } \\
\text { High }\end{array}$ & $\begin{array}{l}\text { Refers to the level of the floodwaters above ground level } \\
\text { measured by the water flow sensor }\end{array}$ \\
\hline & Steeper slopes/relief & $\begin{array}{l}\text { Low } \\
\text { Average } \\
\text { High }\end{array}$ & Refers to the slope of the land that affects waterflow speed \\
\hline Output & Warning system & $\begin{array}{l}\text { Normal (N) } \\
\text { Cautious (C) } \\
\text { Dangerous (D) }\end{array}$ & \\
\hline
\end{tabular}


Table 2 The range of input

\begin{tabular}{llll}
\hline No & Input membership function (IMF) & The range of input membership functions \\
\hline 1 & Rainfall intensity & Small & $0-15 \mathrm{~mm} / \mathrm{d}$ \\
& Moderate & $10-30 \mathrm{~mm} / \mathrm{d}$ \\
& Heavy & $20-50 \mathrm{~mm} / \mathrm{d}$ \\
& Storm & $40-75 \mathrm{~mm} / \mathrm{d}$ \\
& Large storm & $65-100 \mathrm{~mm} / \mathrm{d}$ \\
& Water speed & Slow & $<40 \mathrm{~m} / \mathrm{s}$ \\
& & Average & $20-80 \mathrm{~m} / \mathrm{s}$ \\
3 & Wast & $>60 \mathrm{~m} / \mathrm{s}$ \\
& Water level & Low & $<4 \mathrm{~cm}$ \\
& Average & $2-8 \mathrm{~cm}$ \\
4 & High & $>6 \mathrm{~cm}$ \\
& Steeper slopes & Low & $<40 \%$ \\
& Average & $20-70 \%$ \\
& High & $>60 \%$ \\
\hline
\end{tabular}

Table 3 Some formulas used in fuzzy rules

\begin{tabular}{|c|c|c|c|c|c|}
\hline \multirow[t]{2}{*}{ Rule number } & \multicolumn{4}{|l|}{ Input } & \multirow{2}{*}{$\begin{array}{l}\text { Output } \\
\text { Warning system }\end{array}$} \\
\hline & $\begin{array}{l}\text { Rainfall intensity } \\
\text { (RI) }\end{array}$ & $\begin{array}{l}\text { Water speed } \\
\text { (WS) }\end{array}$ & Water level (WL) & $\begin{array}{l}\text { Steeper slopes } \\
\text { (SS) }\end{array}$ & \\
\hline 1 & Small & Very slow & Low & Very low & Normal \\
\hline 2 & Moderate & Very slow & Low & Very low & Normal \\
\hline 3 & Moderate & Slow & Low & Very low & Normal \\
\hline 4 & Moderate & Average & Average & Average & Cautious \\
\hline 5 & Heavy & Average & Average & Average & Cautious \\
\hline 6 & Moderate & Fast & Average & Average & Cautious \\
\hline 7 & Heavy & Fast & Average & Average & Cautious \\
\hline 8 & Heavy & Fast & High & High & Dangerous \\
\hline 9 & Storm & Fast & High & High & Dangerous \\
\hline 10 & Large Storm & Fast & High & High & Dangerous \\
\hline
\end{tabular}

technical knowledge describing the expected system behavior is contained in many data collections. In this way, system designers can only artificially seek the if-then fuzzy rules from these data collections, and this work often requires the collection of a large number of data collections and a lot of effort.

Each membership function has an important role in determining the potential for flooding in mountainous areas of Indonesia. Because the intensity of rainfall has the greatest influence on flooding (then in this prefix the variable is divided into five) if the rainfall intensity is abnormal, it triggers another membership function.

\section{Related research}

Babu et al. [7] proposed an alert system to monitor efficiently critical flood-prone and earthquake areas on a real-time basis. They used a water level sensor, rain sensor, and MPU6050 sensor as the main focus of their study and examined how the water level 
sensor detects floods and the vibration sensor detects earthquakes simultaneously. In their system, the messages are sent via global system for mobile communications (GSM), and when flood-prone areas occur, they provide solar energy through the solar panel to charge the entire system. As a result, this system can send packet data to the ThingSpeak cloud server via the internet, and the global positioning system (GPS) installation can track people who are affected by floods and earthquakes. Shankar et al. [8] proposed a system to detect the impending flood and monitor any other climate parameters, by the weather forecast and rain sensor. They use an ultrasonic sensor, water level sensor, and water flow sensor in their study and tried to determine water level in dams, rivers and kept track of the rate of flow of water, whose values are displayed on the liquid crystal display, The data is then sent to the blynk App. Light-emitting diode (LED) and buzzer are for a dangerous situation, and an alert message is sent through the blynk App and SMS through the GSM modem. As a result, their parameter can be updated once every three hours to monitor the parameters that may cause flooding. In their study, Devaraj Sheshu et al. [9] aimed to alert the authorities about an imminent flood by monitoring the water level in the sewage system in urban areas. They used sensors to obtain the realtime data on water level of water bodies and the flow rates. The data were transferred to the controller over Wi-Fi using NodeMCU. The controller Raspberry Pi 3 will update the sensor data graph on the website and provide weather data from the internet. The result is an alert will be provided if the values are not within the safe levels. The sign includes a buzzer sound and also an SMS to the concerned authority using the Twilio platform.

In the study by Saragih et al. [10], the authors proposed an AIoT system that can monitor reservoirs. They used an ultrasonic sensor as the primary focus of their study to assess the difference between the use of an ultrasonic sensor and control using a stepper motor. The sensor used can measure water level and water volume. The system was designed in real-time based on the AIoT with a web interface so that the public could directly monitor it. The outcome was the installation of the ultrasonic sensor and the stepper motor to determine water level activity from low to high levels with high output displayed on the serial monitor and web server. Likewise, Ali et al. [11] proposed an early flood detection, warning, and notification system. They used a flow sensor, sonar sensor, and rain detector as the main focus of their study and examined real-time data collection on the riverbanks with onsite sensors. This telemetry data was sent to an online platform for processing. The result is showed that this system is very efficient and very useful in the practical by testing the water instantly, as shown in Fig. 2.

\section{The proposed system}

\subsection{System architecture}

Figure 3 shows the system architecture of this study. The architecture of the system includes three different layers: the physical layer, the network layer, and the application layer. In the physical layer, some sensors are connected to the network layer that has LoRa and subscriber identity module (SIM) cards. All sensor readings from each post are displayed on the App, and an alert will be sent via SMS and App. 


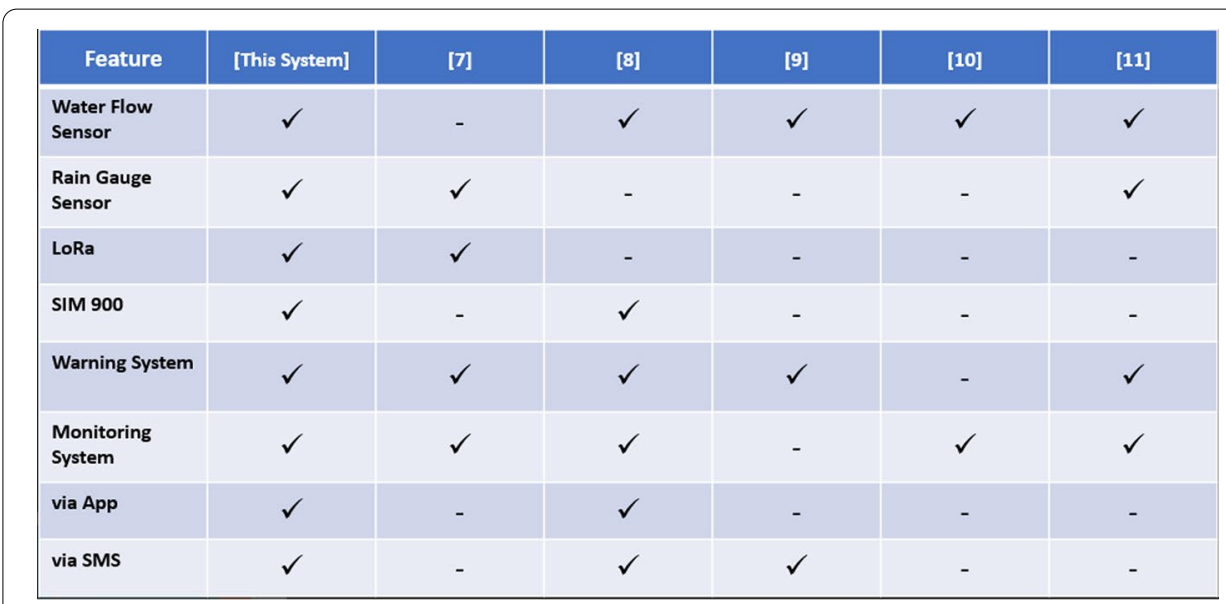

Fig. 2 Feature comparison. This telemetry data was sent to an online platform for processing. The result is showed that this system is very efficient and very useful in the practical by testing the water instantly

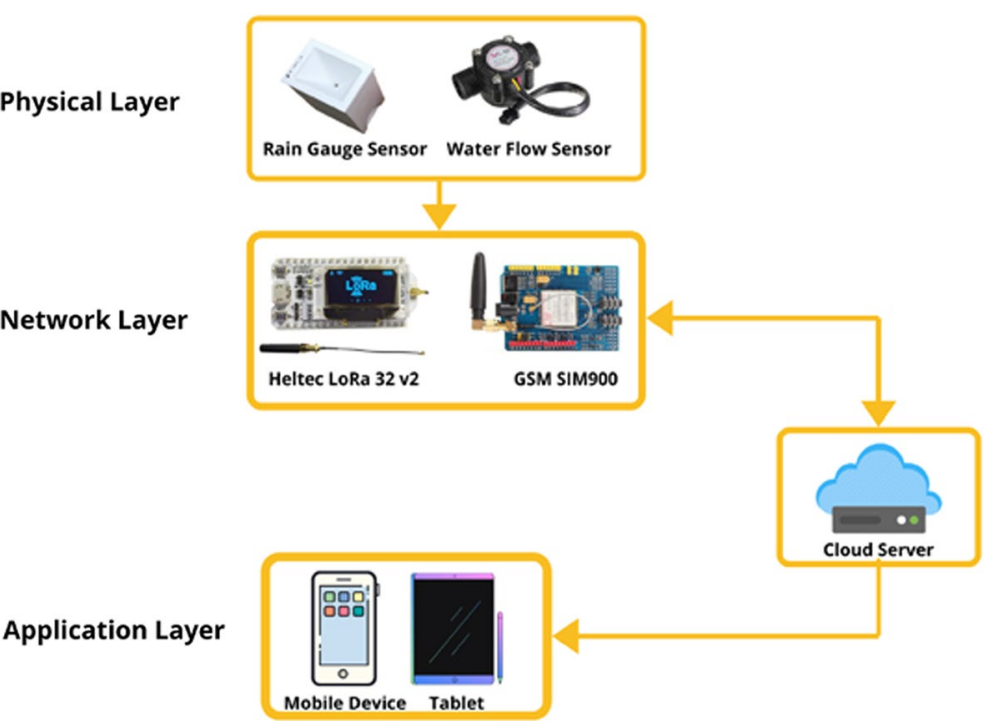

Fig. 3 System architecture. The architecture of the system includes three different layers: the physical layer, the network layer, and the application layer. In the physical layer, some sensors are connected to the network layer that has LoRa and SIM cards

\subsection{Hardware}

\subsubsection{Heltec LoRa 32}

LoRa has become a key enabler for multiple LPWAN technologies [12]. It is a modulation technique derived from chirp spread spectrum (CSS) technology. While there are many types of LoRa, the one used in this study was Heltec LoRa 32. It has three wireless features: Bluetooth 4.2, Wi-Fi 802.11, and the LoRa, and all of this can be used simultaneously. This type of network with a reach of $3.6 \mathrm{~km}$ is through a simple antenna. Figure 4 shows the hardware structure of the front Heltec LoRa 32. 

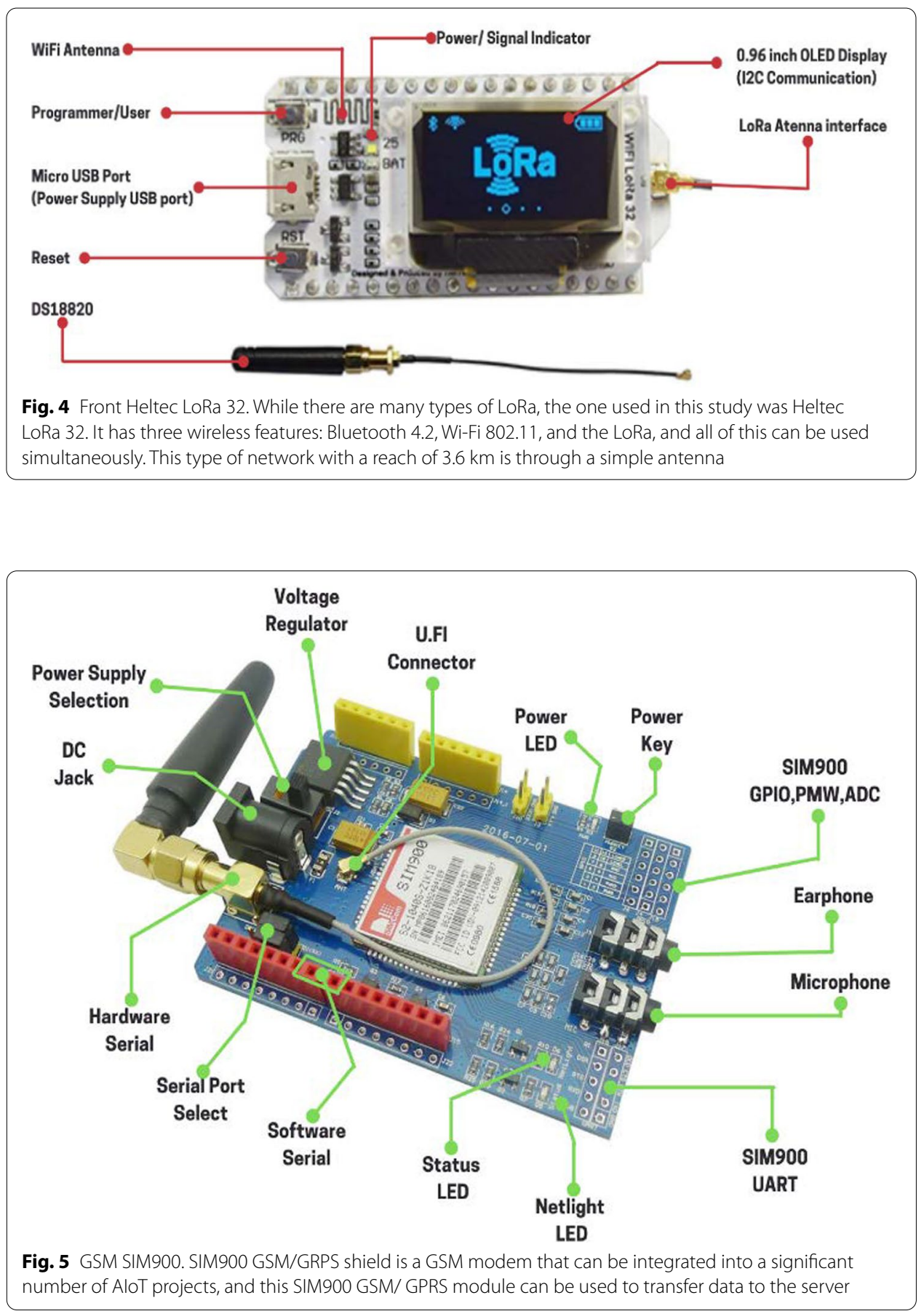

\subsubsection{GSM SIM900}

Figure 5 is the GSM SIM900 structure. SIM900 GSM/general packet radio service (GPRS) shield is a GSM modem that can be integrated into a significant number of AIoT projects, and this SIM900 GSM/GPRS module can be used to transfer data to the server [13]. This one can connect to the internet over a GPRS network, send and receive a message, and place and receive phone calls. 


\subsubsection{Rain gauge sensor}

Figure 6 is a type of rain gauge which has a tipping bucket. Per tip is 0.053 inches or $1.346 \mathrm{~mm}$ of rain. Furthermore, this rain gauge has a magnetic sensor, which works when the magnet attached to the tipping-bucket moves a magnetic switch as a tipping bucket, thereby affecting each tip's momentary switch closure. The rain data is saved in a data logger, which records the time of each tip. The devising of more inexpensive mid-range and long-range radio systems for Wireless Sensors Networks (WSNs) makes this type of sensor more practical and robust in studying rainfall over a wide geographic area [14].

\subsubsection{Water flow meter sensor}

The water flow sensor consists of a copper body, a water rotor, and a hall-effect sensor. When water flows through the rotor, the rotor rolls its speed changes with different flow rates and the hall-effect sensor outputs the corresponding pulse signal. In this study used a water flow meter sensor Sub Robotics YF-S201 which can work up to $30 \mathrm{~L}$ of water per minute, work at temperatures of -25 to $80{ }^{\circ} \mathrm{C}$, and at $35-80 \% \mathrm{RH}$ humidity. This water flow sensor will record the amount of water and all this data can then be sent to the server via LoRa and SIM900 [15]. See Fig. 7, for hardware structure.

\subsubsection{Tilt (inclinometer) sensor}

Figure 8 is a high-precision tilt sensor's structure. The tilt sensor uses an accelerometer to measure tilt angles between $0^{\circ}$ and $180^{\circ}$ with a precision of $0.1^{\circ}$. However, for detecting the slope on the slope, it is only used between $0^{\circ}$ and $45^{\circ}$ because the slope angle that exceeds the threshold can affect the flow of water during flooding. This sensor is also equipped with an internal LoRa-based antenna which has a very wide range. This sensor has a battery capacity of up to 5-10 years depending on usage; it can also withstand temperatures between -40 and $+70{ }^{\circ} \mathrm{C}$ during operation and $+100{ }^{\circ} \mathrm{C}$ when in storage.

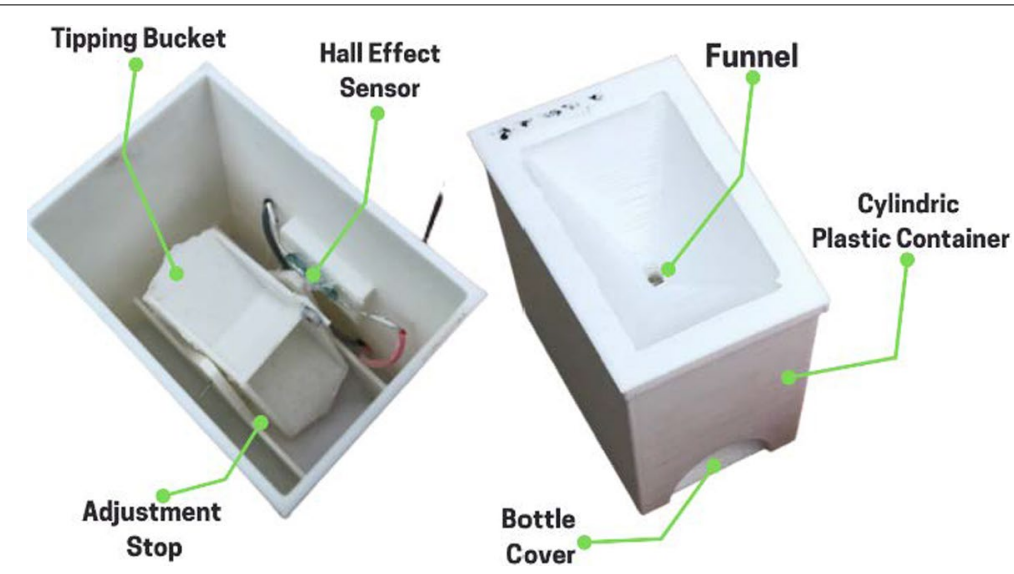

Fig. 6 Rain gauge sensor. Per tip is 0.053 inches or $1.346 \mathrm{~mm}$ of rain. Furthermore, this rain gauge has a magnetic sensor, which works when the magnet attached to the tipping bucket moves a magnetic switch as a tipping bucket, thereby affecting each tip's momentary switch closure 


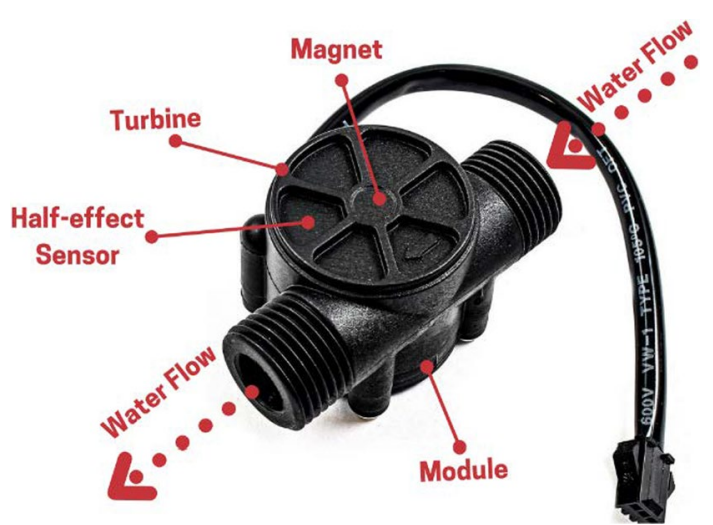

Fig. 7 Water flow meter sensor. This water flow sensor will record the amount of water and all this data can then be sent to the server via LoRa and SIM900

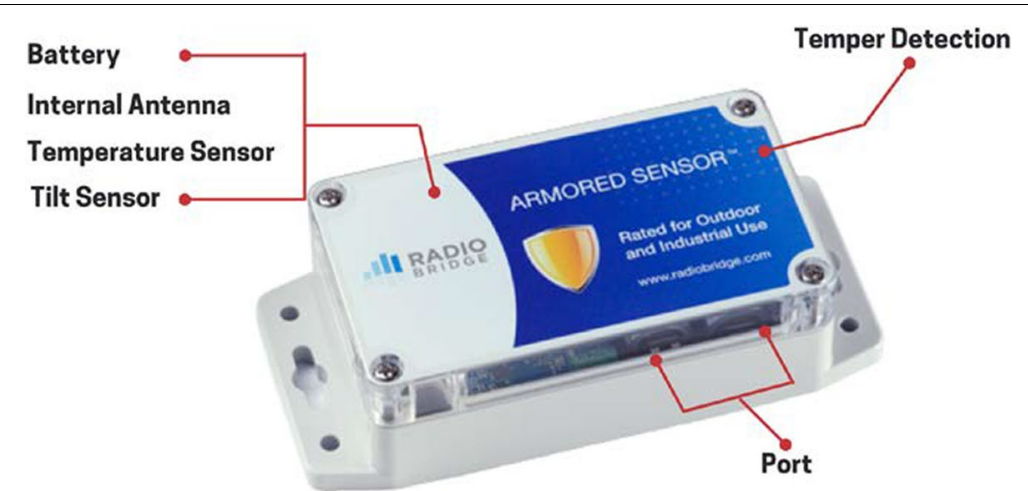

Fig. 8 Tilt sensor. The tilt sensor uses an accelerometer to measure tilt angles between $0^{\circ}$ and $180^{\circ}$ with a precision of $0.1^{\circ}$. However, for detecting the slope on the slope, it is only used between $0^{\circ}$ and $45^{\circ}$ because the slope angle that exceeds the threshold can affect the flow of water during flooding

\subsection{Software}

Figure 9 is a flowchart that shows the working system. The sensor system detects the data by using the fuzzy method that the system will determine the output variable in the system. The data is then be sent to the cloud management platform for data processing and then to the application for real-live data and flood early warning via SMS and Application.

\section{Presentation of result}

As previously discussed, rainfall intensity has an important role in determining the potential for flooding on mountain slopes in Indonesia. In the rules menu, we can set the desired result of the warning system, but in the experimental example in this study, we used the default rules from Matlab. The results are presented in Fig. 10a and b. As shown in Fig. 10b, rainfall intensity has an important role in determining the potential for flooding in mountainous areas in Indonesia. On the graph, the blue color indicates a small rainfall so that it does not have much impact on the potential for flooding, followed by a light blue color which indicates moderate rainfall, then is 


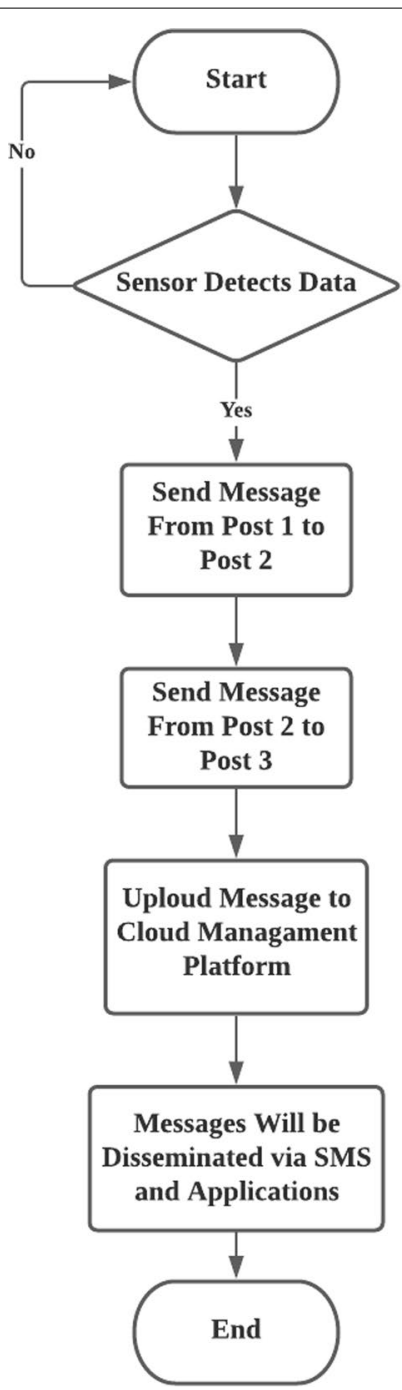

Fig. 9 System flowchart. The sensor system detects the data by using the fuzzy method that the system will determine the output variable in the system. The data is then be sent to the cloud management platform for data processing and then to the application for real-live data and flood early warning via SMS and Application

the color Tosca which indicates heavy rainfall, and finally yellow color indicates storm rainfall and large storm. From this, we realize that the warning from the system starts working on the light blue graph (moderate rainfall) and above.

During trial and error, some abnormal data were obtained when incorrectly determining the rules in this fuzzy method. As shown in Fig. 11a, this abnormal data occurs when incorrectly setting the rules where the steeper slopes and water level rules seem to fluctuate which makes the system difficult to read and determine the right output. On the other hand, according to Fig. 11b, it looks normal from the rainfall intensity side but an uphill water slope results in abnormal data, because the rainfall intensity has the most influence in determining the potential for flooding, although here we can see the region of slow rainfall intensity but with sudden uphill water slope. When 


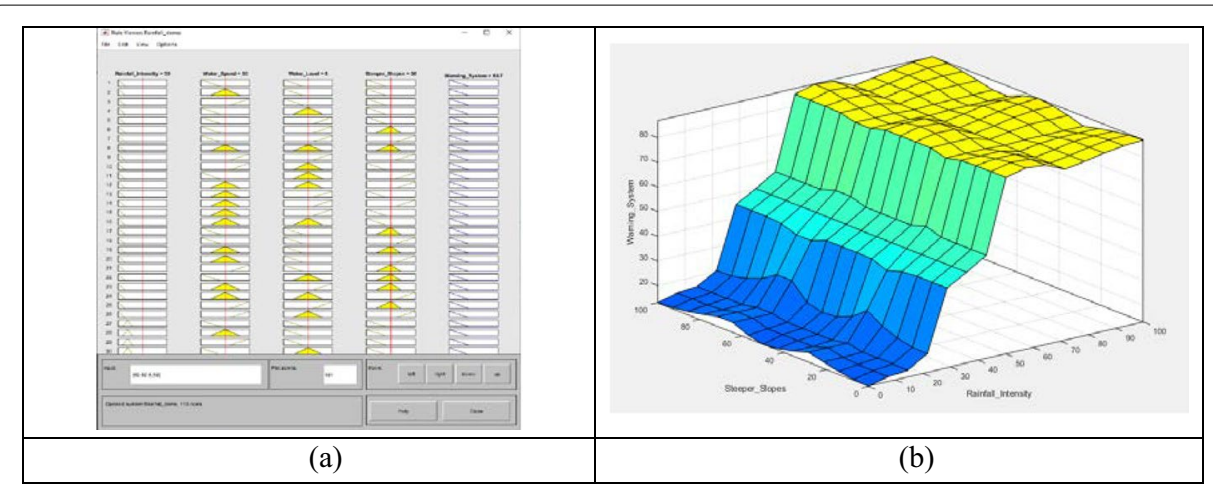

Fig. 10 Graphic result a rules; $\mathbf{b}$ warning system (Z-axis) with the input parameter of water level (Y-axis), and rainfall intensity ( $X$-axis). Rainfall intensity has an important role in determining the potential for flooding in mountainous areas in Indonesia. On the graph, the blue color indicates a small rainfall so that it does not have much impact on the potential for flooding, followed by a light blue color which indicates moderate rainfall, then is the color

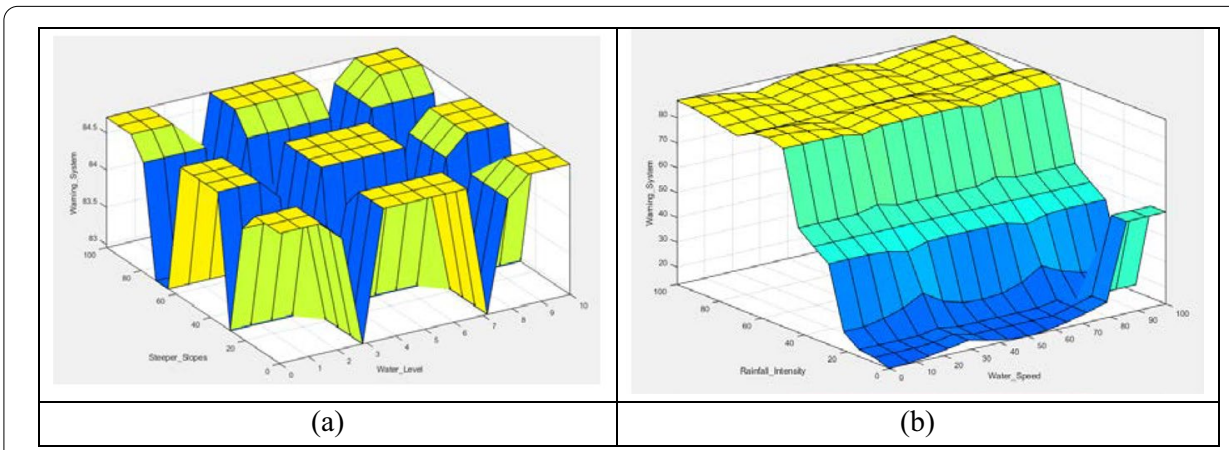

Fig. 11 Abnormal graphic result a warning system (Z-axis) with the input parameter of steeper slopes ( $Y$-axis) and water level $(X$-axis); $\mathbf{b}$ warning system (Z-axis) with the input parameter of rainfall intensity $(Y$-axis) and water speed (X-axis). It looks normal from the rainfall intensity side but an uphill water slope results in abnormal data, because the rainfall intensity has the most influence in determining the potential for flooding, although here we can see the region of slow rainfall intensity but with sudden uphill water slope

the rainfall intensity is slow all input membership functions should not be affected. That is why Fig. 11b is included in the abnormal graphic.

\section{Analysis of the mathematical model of this research}

After field surveys and multi-stakeholder discussions, early warning methods were analyzed, based on two parameters, namely the intensity of rainfall and flood timing.

\subsection{Intensity of rainfall}

The Gumbel theory of distribution is used to distribution for intensity duration frequency (IDF) analysis because it is suitable for modeling maxima. It is simple and used only when extreme events occur (maximum values or peak rainfalls). The formula is as follows:

$$
P_{T}=P_{\text {ave }}+K S
$$


In the formula, $P_{T}$ : Frequency precipitation (in $\mathrm{mm}$ ) for each duration with a specified return period T (in a year), $P_{\text {ave }}$ : Average of the maximum precipitation corresponding to a specific duration, $K$ : Gumbel frequency factor, $S$ : Standard deviation of $\mathrm{P}$ data.

Where each factor is given by:

$$
\begin{aligned}
& K=\frac{\sqrt{ } 6}{\pi}\left[0.5772+\ln \left[\ln \left[\frac{T}{T-1}\right]\right]\right] \\
& P_{\text {ave }}=\frac{1}{n} \sum_{i=1}^{n} P I \\
& S=\left[\frac{1}{n-1} \sum_{i=1}^{n}(\text { Pi }- \text { Pave })^{2}\right]^{1 / 2}
\end{aligned}
$$

The frequency factor $(\mathrm{K})$ multiplied by the standard deviation gives the departure of desired return period rainfall from the average. Then the rainfall intensity $\left(\mathrm{I}_{\mathrm{T}}\right)$ is obtained using the formula:

$$
I_{T}=\frac{P t}{T d}
$$

In the formula, $P_{T}$ : Frequency precipitation (in $\mathrm{mm}$ ) for each duration with a specified return period $\mathrm{T}$ (in a year), $T_{d}$ : Duration in hours.

\subsection{Timing of flood}

To calculate the timing of flood/ concentration period, the formula is as follows:

$$
t_{p}=C A^{0.22} r e^{-0.35}
$$

In the formula, $t_{p}$ : the timing of flood arrival (minute), re: effective rainfall intensity (mm/hour), $A$ : Catchment area $\left(\mathrm{km}^{2}\right), C$ : Coefficient.

Another equation that may be used is the Izzard equation, where some topographic factors are considered as contributing factors (distance of stream surface, slope of the field, both forming a restriction coefficient for the runoff flow and the concentration period). The formula is as follows:

$$
t c=\left(\frac{4 I L^{1 / 3}}{i^{2 / 3}}\right)\left(\frac{0.0007 i+c r}{s^{1 / 3}}\right)
$$

In the formula, $t c$ : Concentration time, L: Length of flow, I: Intensity of rainfall, cr: Coefficient of flow resistance, $\mathrm{s}=$ slope of the field.

\subsection{Steeper slopes}

A steeper slope is a line that describes the direction and the steepness of a line. Slope can be expressed in angles, gradients, or grades.

a. Slope expressed as an angle 
To calculate steeper slope expressed in angle, the formula is as follows:

$$
S_{\text {angle }}=\tan ^{-1}(y / x)
$$

In the formula, $S_{\text {angle }}$ : angle ( $\mathrm{rad}$, degrees $\left(^{\circ}\right)$ ), $x$ : Horizontal run, $y$ : Vertical run.

b. Slope expressed as the gradient

To calculate Steeper slope expressed in gradient, the formula is as follows:

$$
S_{\text {grade }}=(100 \%) y / x
$$

In the formula, $S_{\text {grade: }}$ grade (\%), $x$ : Horizontal run, $y$ : Vertical run.

\section{Discussion and analysis of experimental results}

The result of this study is a prototype of the flood detection tool, its application, and the use of SMS. This flood detection application is based on the android function, which can display rainfall data and water velocity on a regular basis and display early warning notifications about flooding, which can be seen in the bell sign on the home page. Figure 12a shows the options for POST, Rainfall Data, and Water Flow Data. Figure 12b shows the water velocity and rainfall intensity in each post as a whole, while Fig. 12c shows the water velocity data that has been recorded every $10 \mathrm{~min}$, making it easier for users to monitor the condition of the water in the river. Figure $12 \mathrm{~d}$ shows the rainfall amount and duration data on the rainfall data page at every $10 \mathrm{~min}$. All data collected from this monitoring will facilitate the system in detecting impending floods.

This study also provides an early warning notification of flooding via SMS as shown in Fig. 13, to people around mountainous slopes who cannot use the application. Notification via SMS will not be stopped until the user sends a reply message in the form of the word STOP. The notification consists of three levels in early warning: yellow, orange, and red. The yellow sign indicates impending rainfall, the orange sign indicates heavy rain and the potential for landslides, and the red sign indicates a possibility of flash flood.

This prototype consists of two parts, as shown in Fig. 14a. The first one is for the cage as shown in Fig. 14b; the material used for the cage box for the bottom used concrete and for the cage used to iron that has been painted with anti-rust coating. Figure 15a shows the image of essential tools. An iron box is used that has been painted with an anti-rust coating with red color, and the box can open. There is an indicator light red button in the front compartment to turn the appliance on and off, yellow for error, and green for correct. So, the condition of this tool can be assessed without the need for opening up the box to see the contents of the devices. There are two sensors here. The first one is the rain gauge sensor as shown in Fig. 15a. This rain gauge sensor already has a hole in the box and cage so that the calculated water can be expelled directly into the ground. This type of rain gauge has a tipping bucket, so when the raindrop goes inside the sensor, the magnetic sensor moves a magnetic switch and affecting each tip momentary switch closure.

The rain data will be saved in a data logger, which records the time of each tip. The second part is the water flow sensor as shown in Fig. 15b. This sensor consists of a copper body, a water rotor, and a hall-effect sensor. When the water flows through the 


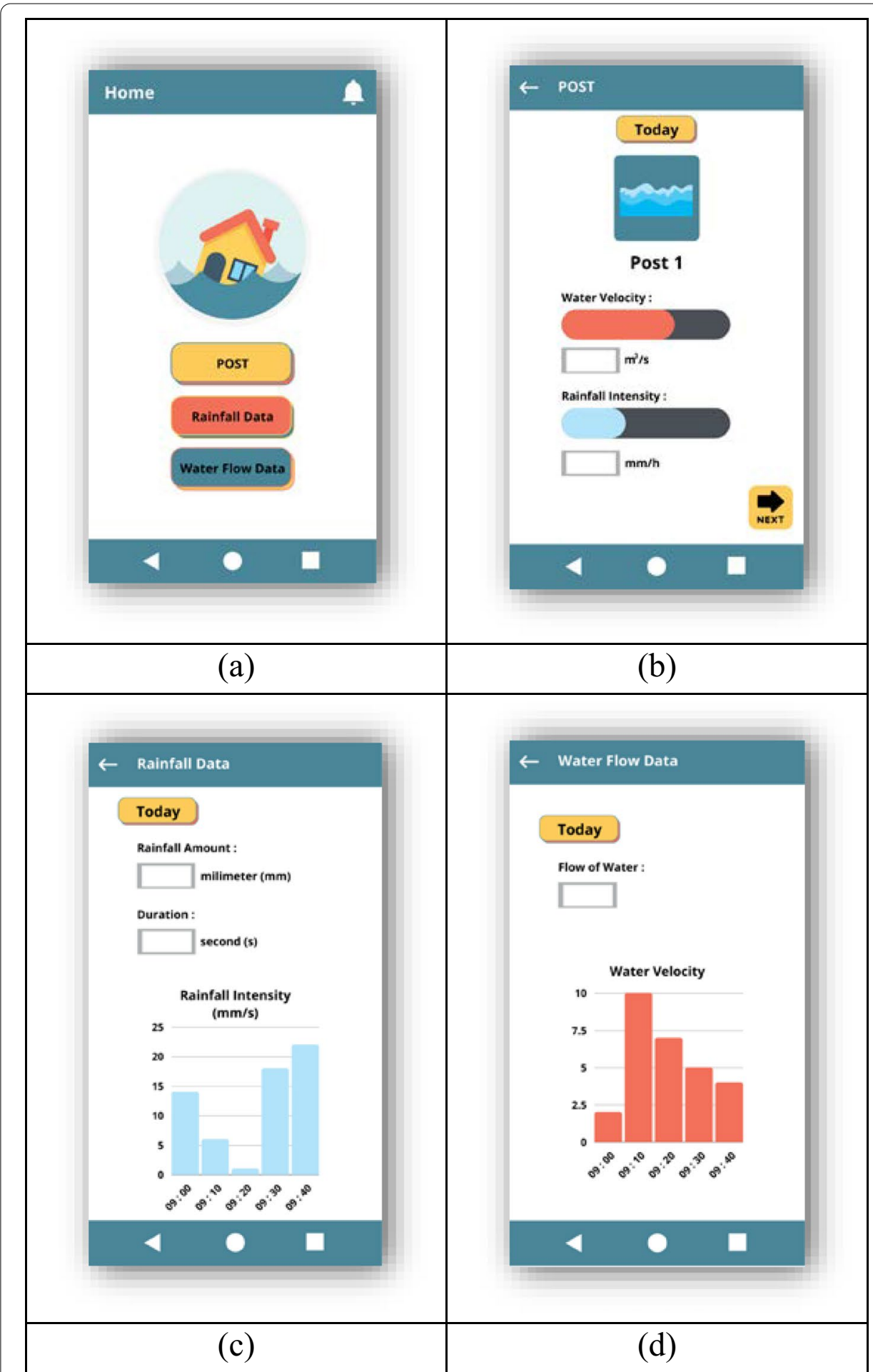

Fig. 12 Flood app display a home page; b POST page; $\mathbf{c}$ water flow data page; $\mathbf{d}$ rainfall data page. This flood detection application is based on the android function, which can display rainfall data and water velocity on a regular basis and display early warning notifications about flooding, which can be seen in the bell sign on the home page 


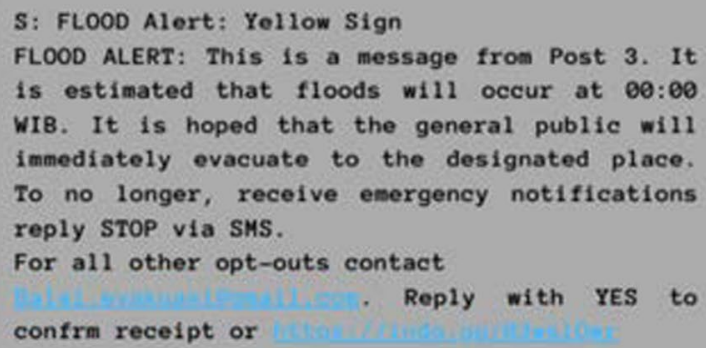

Fig. 13 Early Warning via SMS. This study also provides an early warning notification of flooding via SMS to people around mountainous slopes who cannot use the application

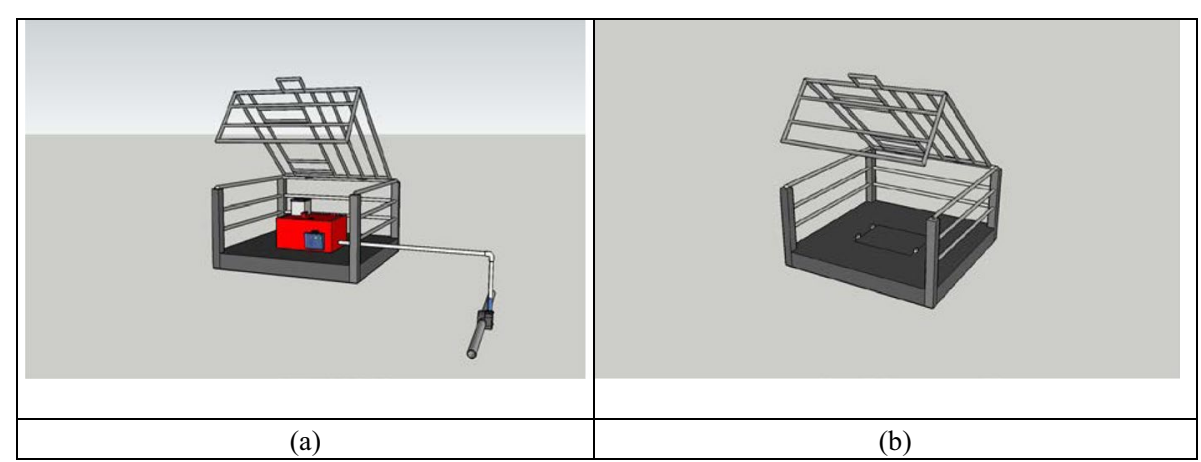

Fig. 14 The hardware devices of the entire outdoor monitoring system a the protective iron frame and the main body of the sensing device; $\mathbf{b}$ the system's protective peripheral frame. This prototype consists of two parts. The first one is for the cage; the material used for the cage box for the bottom used concrete and for the cage used to iron that has been painted with anti-rust coating

rotor, the rotor rolls its speed changes with different flow rates, giving a corresponding pulse signal. The flood disasters of mountain rivers due to rainfall and various secondary disasters have become one of the main geological disasters faced by mountainous areas. Mountain torrents have the characteristics of large flow, fast speed, strong scouring ability, and carry a large amount of sand and rocks. Once a disaster occurs, it will have a huge impact on the life and property safety of the local people. Thus, scientific and reasonable measures must be undertaken to protect the life safety of the people and reduce property, making flood monitoring and early warning of rivers particularly important and urgent. However, this study has a few limitations such as a complex regional geological environment, wide monitoring range, inconvenient transportation, poor communication conditions, and limited capital investment. At 


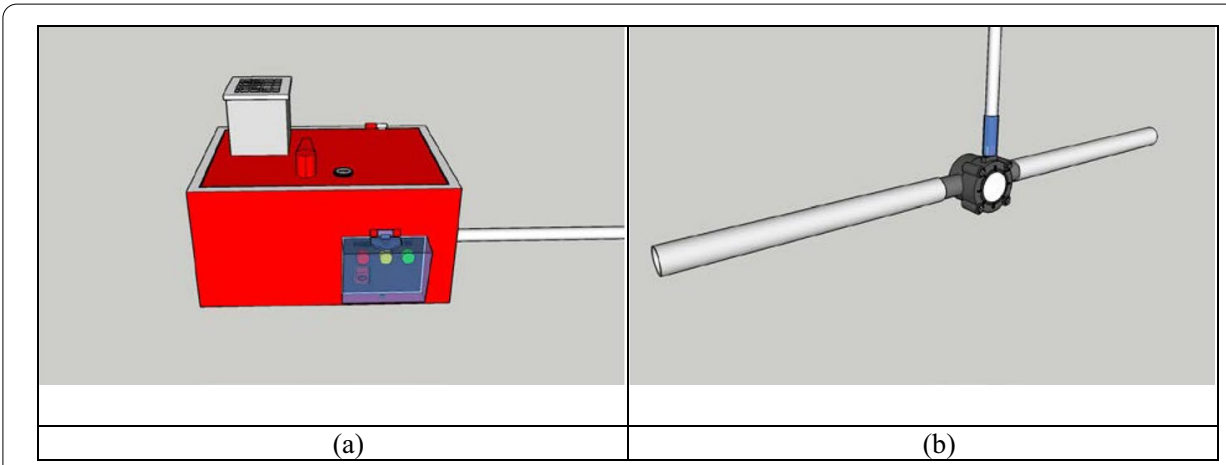

Fig. 15 Sensor and microcontroller device $\mathbf{a}$ basic microcontroller circuit and sensor connection, $\mathbf{b}$ the water flow sensor. The first one is the rain gauge sensor. The rain data will be saved in a data logger, which records the time of each tip. The second part is the water flow sensor

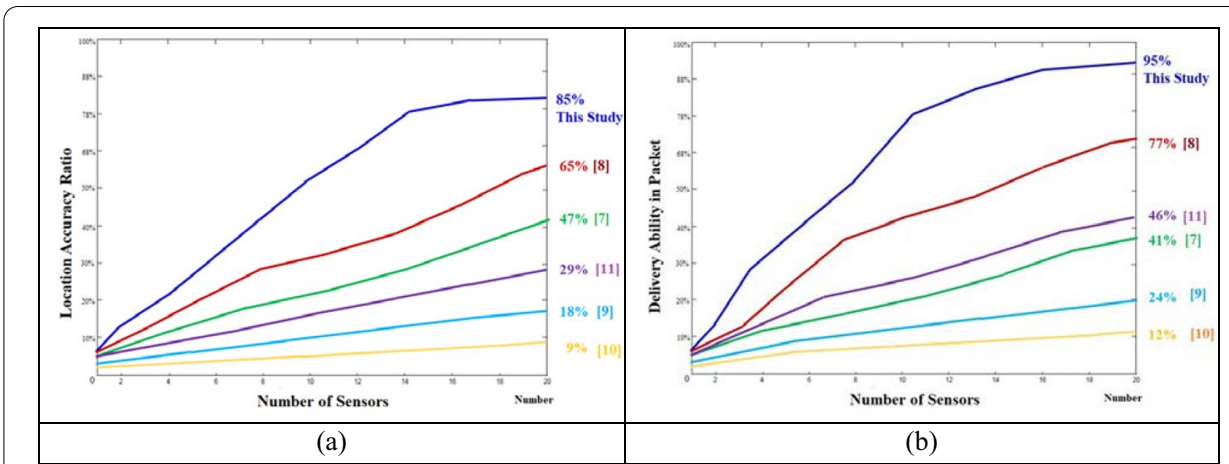

Fig. 16 a Accuracy of location versus the number of sensors; $\mathbf{b}$ pack delivery capacity versus the number of sensors. That as the signal dwell time increases, fewer position updates are required. The influence of the number of sensors on the cost of packet delivery is represented

this stage, the commonly used flood monitoring and early warning methods cannot solve the above problems simultaneously. In response to the above situation, this research designed a special plan for flood monitoring and early warning in mountainous areas, and achieved the following results:

(1) A complete research on key technologies for flood monitoring and early warning in mountainous rivers.

(2) The flood monitor was successfully developed and used to realize remote real-time monitoring of floodwater levels.

(3) A monitoring and early warning system were built to integrate flood level monitoring, regional rainfall monitoring, remote wireless transmission, GSM conversion, and other technologies.

(4) The study involves electronics, geology, disasters, and other disciplines, reflecting the practice and exploration of interdisciplinary research in the field of disaster monitoring and early warning.

(5) The research on key technologies of monitoring and early warning have been closely integrated with practical applications, and the remote flood monitoring and early warning of the river basin have been launched. 
Figure 16a and $\mathrm{b}$ show that as the signal dwell time increases, fewer position updates are required. The influence of the number of sensors on the cost of packet delivery is represented in Fig. 16a and b. Figure 16a shows the ratio of the number of sensor nodes to the accuracy of the system's position calculations. The greater the number of sensors in the system, the higher the accuracy of its positioning. The proposed system yielded accuracy at least $31 \%$ higher than the prevalent system. Figure 16b shows whether the capacity for packet transmission decreased when more sensors were used. When the number of sensor nodes increased, the capacity of packet transmission was higher than that reported in earlier studies [7-11, 16-18].

\section{Conclusions}

This study focused on monitoring and providing early warnings about flooding on mountain slopes. Floods are dangerous natural disasters because floods can also cause casualties and drown the victims' property. In this study, we present a tool that can monitor and predict the occurrence of floods through SMS and Applications, which is expected to help people evacuate them as early as possible. Due to internet network issues in the mountains, this research focused more on using LoRa in sending messages between devices. We used the fuzzy method to calculate and analyze various environmental variables. The results of analysis in Indonesia indicate that the intensity of rainfall has an important role in determining the potential for flooding on mountain slopes because it can affect other factors such as water velocity and water level. The trial and error results led to some abnormal data when incorrectly determining the rules in this fuzzy method. This abnormal data occurs when the rules are incorrectly set, wherein the steeper slopes and water level rules seem to fluctuate, making the system difficult to read and determine the right output. In the future, we hope that more parameters can be added and developed to provide more accurate analysis results in detecting floods, especially on mountain slopes.

The accuracy of this research on the rainfall warning method is very high. Through the analysis of the rainfall warning model of the mathematical model of this research, the research on related parameters of flood monitoring such as soil saturation was added, and the advantages of the GSM sending module were used for real-time transmission of all users. The communication network in this study uses the LoRa plus GSM mode to carry out efficient and convenient data transmission even in the signal blind zone of the mobile network and fully realize the wireless communication for monitoring and early warning.

\section{Abbreviations}

AloT: Artificial intelligence Internet of things; LoRa: Long range; LPWAN: Low-power wide-area network; SMS: Short message service; GSM: Global system for mobile communications; GPS: Global positioning system; LED: Light-emitting diode; SIM: Subscriber identity module; CSS: Chirp spread spectrum; GPRS: General packet radio service; WSNs: Wireless Sensors Networks; IDF: Intensity duration frequency.

\section{Acknowledgements}

This research was supported by the Department of Electrical Engineering, National Chin-Yi University of Technology. The authors would like to thank the National Chin-Yi University of Technology, Takming University of Science and Technology, Taiwan, for financially supporting this research.

Authors' contributions

W-TS is responsible for research planning and providing improvement methods. I-VD and S-JH is responsible for thesis writing and experimental verification. All authors read and approved the final manuscript. 


\section{Funding}

The author(s) received no specific funding for this study.

Availability of data and materials

Data sharing not applicable to this article as no datasets were generated or analyzed during the current study.

\section{Declarations}

\section{Competing interests}

The authors declare that they have no conflicts of interest to report regarding the present study.

\section{Author details}

${ }^{1}$ Department of Electrical Engineering, National Chin-Yi University of Technology, Taichung 411030, Taiwan. ${ }^{2}$ Department of Information Technology, Takming University of Science and Technology, Taipei City 11451, Taiwan.

Received: 8 September 2021 Accepted: 20 February 2022

Published online: 04 March 2022

\section{References}

1. G. Nagle and B. Cooke, Option a freshwater-drainage basins, in Geography (2nd edn), (Oxford University Press, United Kingdom, 2017), p. 16-27

2. P. Panagos, P. Borrelli, K. Meusburger, Global rainfall erosivity assessment based on high-temporal resolution rainfall records. Sci. Rep. 7, 4175 (2017)

3. F. R. Shaw, A. Mallick, N. Islam, Disaster risk reduction approaches in Bangladesh, in Disaster Risk Reduction Approaches in Bangladesh, Disaster Risk Reduction 1st edn. (Springer, Japan, 2013), p. 165-189.

4. H. N. Saha, Disaster management using Internet of Things, in 8th Annual Industrial Automation and Electromechanical Engineering Conference (IEMECON) (Bangkok, Thailand, 2017), p. 81-85.

5. W.-T. Sung, J.-S. Hsiao, S.-Y. Wang and J.-H. Chou, LoRa-based internet of things secure localization system and application, in IEEE International Conference on Systems, Man and Cybernetics (SMC) (Bari, Italy, 2019), p. 1672-1677

6. A. Augustin, J. Yi, T. Clausen, W.M. Townsley, A study of LoRa: long range and low power networks for the internet of things. Sensors 16(9), 1-18 (2016)

7. V. Babu and V. Rajan, Flood and earthquake detection and rescue using loT technology, in International Conference on Communication and Electronics Systems (ICCES) (Coimbatore, India, 2019), p. 1256-1260

8. S. Shankar, J. J. Jijesh, D. R. Bolla, M. Penna, P. V. Sruthi et al., Early detection of flood monitoring and alerting system to save human lives, in International Conference on Recent Trends on Electronics, Information, Communication and Technology (RTEICT) (Bangalore, India, 2020), p. 353-357

9. E. D. Sheshu, N. Manjunath, S. Karthik and U. Akash, Implementation of flood warning system using loT, in Second International Conference on Green Computing and Internet of Things (ICGCloT) (Bangalore, India, 2018), p. 445-448

10. Y. Saragih, J. H. P. Silaban, H. A. Roostiani and S. A. Elisabet, Design of automatic water flood control and monitoring systems in reservoirs based on internet of things (loT), 3rd International Conference on Mechanical, Electronics, Computer, and Industrial Technology (MECnIT) (Medan, Indonesia, 2020), p. 30-35.

11. S. A. Ali, F. Ashfaq, E. Nisar, U. Azmat and J. Zeb, A prototype for flood warning and management system using mobile networks, in 17th International Bhurban Conference on Applied Sciences and Technology (IBCAST) (Islamabad, Pakistan, 2020), p. 326-331

12. P. Edward, M. El-Aasser, M. Ashour, T. Elshabrawy, Interleaved chirp spreading LoRa as a parallel network to enhance LoRa capacity. IEEE Internet Things J. 8(5), 3864-3874 (2021)

13. G. Tatar, O. Kilıç and S. Bayar, FPGA based fault distance detection and positioning of underground energy cable by using GSM/GPRS, in International Symposium on Advanced Electrical and Communication Technologies (ISAECT) (Rome, Italy, 2019), p. 1-6.

14. O. Omoruyi, S. N. John, O. Chinonso, O. Robert, A. A. Adewale et al., Wireless sensor network for rainfall measurement using a tipping bucket rain gauge mechanism, in International Conference on Computational Science and Computational Intelligence (CSCI) (Las Vegas, NV, USA, 2017), p. 740-744

15. M. M. Srihari, Intelligent water distribution and management system using internet of things, in International Conference on Inventive Research in Computing Applications (ICIRCA) (Coimbatore, India, 2018), p. 785-789

16. I. Riyanto, L. Margatama, A. Ariawan, L. Bayuaji, M. Rizkinia et al., Web camera sensor coupled with lidar data flood map for flood warning system, in International Conference on 2019 IEEE Geoscience and Remote Sensing Symposium (IGARSS) (Yokohama, Japan, 2019), p. 9406-9408

17. V. Balaji, A. Akshaya, N. Jayashree and T. Karthika, Design of ZigBee based wireless sensor network for early flood monitoring and warning system, in International Conference on IEEE Technological Innovations in ICT for Agriculture and Rural Development (TIAR) (Chennai, India, 2017), p. 236-240

18. R. H. Randhawa, R. Mahmood and T. Ahmad, AquaEye: A low cost flood early warning system for developing countries, in International Conference on Frontiers of Information Technology (FIT) (Islamabad, Pakistan, 2018), p. 345-349

\section{Publisher's Note}

Springer Nature remains neutral with regard to jurisdictional claims in published maps and institutional affiliations. 